Article

\title{
Phoenix dactylifera L. Seed Pretreatment for Oil Extraction and Optimization Studies for Biodiesel Production Using Ce-Zr/Al-MCM-41 Catalyst
}

\author{
Zainab Ibrahim Jibril ${ }^{1}$, Anita Ramli ${ }^{1,2, *}$, Khairulazhar Jumbri ${ }^{1}(\mathbb{D}$ and \\ Normawati Mohamad Yunus ${ }^{1}$ (D) \\ 1 Fundamental and Applied Sciences Department, Universiti Teknologi PETRONAS, \\ Seri Iskandar 32610, Perak, Malaysia; zainab_g03666@utp.edu.my (Z.I.J.); \\ khairulazhar.jumbri@utp.edu.my (K.J.); normaw@utp.edu.my (N.M.Y.) \\ 2 HI-CoE Center for Biofuels and Biochemicals Research, Universiti Teknologi PETRONAS, \\ Seri Iskandar 32610, Perak, Malaysia \\ * Correspondence: anita_ramli@utp.edu.my
}

Received: 26 June 2020; Accepted: 5 July 2020; Published: 9 July 2020

check for updates

\begin{abstract}
This work compared the effect of soaking and roasting Phoenix dactylifera L. seeds pretreatment methods on oil yield. The conversion of the Phoenix dactylifera L. seed oil to fatty acid methyl ester (FAME) was conducted via transesterification reaction using Ce-Zr/Al-MCM-41 monometallic and bimetallic catalysts. The reaction conditions were optimized using response surface methodology based on the central composite design (RSM-CCD). The result shows a quadratic model fitting with an $R^{2}$ value of $\sim 0.98 \%$ from the analysis of variance. In addition, the optimum FAME yield of $93.83 \%$ was obtained at a reaction temperature of $60.5^{\circ} \mathrm{C}$, a reaction time of $3.8 \mathrm{~h}$, a catalyst concentration of $4 \mathrm{wt} . \%$, and a methanol to oil molar ratio of $6.2: 1 \mathrm{~mol} / \mathrm{mol}$. The effect of the regenerated catalyst was significantly maintained for five cycles. The fuel properties of the produced FAME lie within the values reported in studies, ASTM D6751, and EN14214 standards.
\end{abstract}

Keywords: bimetallic catalyst; central composite design; monometallic catalyst; Phoenix dactylifera L. seed oil; transesterification reaction

\section{Introduction}

Energy consumption increases with the rise in economic and population growth, leading to problems such as a decline in the fossil fuel reserves and an adverse impact on the environment due to the increase in greenhouse gases (GHG) [1] Thus, extensive research on the alternative energy source to reduce demand on the primary energy source and to tackle the environmental concerns is ongoing, as the highest percentage of the emission of toxic gases comes from the industries and the transport sector [2]. Generally, eco-friendly renewable energy sources and wastes such as biofuels have a higher potential to be used as sources of alternative energy. Liquid biofuels derived from biomass include biodiesel produced using fresh or used vegetable oils and animal fats. Biofuels make a significant contribution as a promising solution to the increasing energy demand on fossil-derived fuels, especially by the transport sector. At the same time, the penetration of biofuels promoted the continuous reduction of toxic gases and improved supply security [3]. The production of biodiesel as a viable alternative to fossil fuel using renewable feedstock and a reusable catalyst has shown promising advantages by contributing to the economic and environmental sustainability development [4,5].

However, the high cost of biodiesel production is the major drawback, resulting in its limited usage as an alternative fuel. The solutions highlighted for the total cost reduction include biodiesel yield improvement, capital, and raw materials costs reduction (especially the feedstock) [1]. Edible vegetable 
oils referred to as first-generation oils such as canola, palm kernel, coconut, and sunflower oil were considered as feedstocks for biodiesel production [6,7]. However, the use of such raw materials amounts to $80 \%$ of the total production cost of biodiesel [5]. For instance, Rahimi et al. [8] concluded that biofuels' sustainable production could be attainable using non-edible energy crops. Thus, non-edible oils, which include waste oils and waste seed oil serve as a substitute feedstock to produce biodiesel. For example, Joshi et al. [9] reported that low-quality non-edible feedstock such as waste cooking oil significantly reduced the biodiesel production cost. Recently, Phoenix dactylifera L. seed oil has attracted the attention of researchers from various fields such as in biodiesel production, as a promising new renewable source that is low-priced and abundant. In fact, it could be considered with a high priority as a potential feedstock that will reduce the total biodiesel production cost. As shown in [7], Phoenix dactylifera L. seed oil biodiesel production cost was lower than that of waste cooking oil, Jatropha oil, sunflower oil, and palm oil.

The Phoenix dactylifera L. tree, commonly known as the date palm, is one of the oldest plants majorly cultivated in arid and semi-arid regions [10]. In 2007, the world annual production of Phoenix dactylifera seed was estimated to be $69,700 \mathrm{t}$ [11], which escalated to an estimate of 1.3 million $\mathrm{t}$ [12]. The palm seed is $6-15 \%$ of the weight of the fruit, oblong in shape, and ventrally grooved with a hard coat that can withstand harsh conditions [13]. Thus, the seeds are inedible and mostly discarded as waste, or as animal feed from date processing plants [14]. The hardness and compactness of the seed's matrix inhibit the extraction of the oil. As such, there is a need for seed pretreatment like grinding and texturing [15]. The grinding or pulverization process of the seeds to powder requires several pretreatment stages such as washing, drying under the sun or roasting, and the use of a heavy-duty grinder. Thus, the availability of a suitable grinder in the laboratory or an alternative method such as soaking to facilitate the grinding process of the hard seeds plays a significant role. For instance, it was found in a study that the ground palm seeds were used as animal feed and for oil extraction after soaking in water for $72 \mathrm{~h} \mathrm{[16].} \mathrm{However,} \mathrm{to} \mathrm{the} \mathrm{best} \mathrm{of} \mathrm{the} \mathrm{authors'} \mathrm{knowledge,} \mathrm{there} \mathrm{is} \mathrm{no} \mathrm{literature} \mathrm{on}$ the possible impact of soaking the seeds on the oil yield for biodiesel production.

Reported studies on the potential use of Phoenix dactylifera L. seed oil as a feedstock for biodiesel production was in the presence of homogeneous catalysts such as $\mathrm{KOH}[17,18]$ and $\mathrm{NaOH}$ [19], in contrast to the limited studies conducted on biodiesel production from Phoenix dactylifera L. seed oil using a heterogeneous catalyst. Examples of the heterogeneous catalysts used for the conversion of Phoenix dactylifera $\mathrm{L}$. seed oil to biodiesel include $\mathrm{CaO}-\mathrm{Fe}_{3} \mathrm{O}_{4}$ nano-magnetic catalyst [20], eggshell derived catalyst [21], $\mathrm{Mn} @ \mathrm{MgO}-\mathrm{ZrO}_{2}$ metallic oxide catalyst [7], and green carbon catalyst [22]. Therefore, there is a need for further studies on biodiesel production from Phoenix dactylifera $\mathrm{L}$. seed oil using a heterogeneous catalyst. The transesterification reaction of vegetable oils is commonly used to produce biodiesel in the presence of methanol and a homogeneous catalyst. Nevertheless, despite the high activity of the homogeneous catalysts at mild reaction conditions, its limitations such as soap formation, wastewater generation, and lack of catalyst reusability paved way for research on heterogeneous catalysts [23]. However, unlike homogeneous catalysts, problems linked to heterogeneous catalysts include mass transfer resistance, limited catalytic active centers, and leaching [24]. Therefore, one of the solutions provided to overcome the disadvantages of using heterogeneous catalysts was making use of supports for the catalysts [25].

The discovery of mesoporous molecular sieves has received immense attention from various fields as a support (or catalyst) for the conversion of bulky molecules due to their properties such as high specific surface area and adjustable pore size [26]. For biodiesel production, metals are incorporated into the mesoporous molecular sieves framework to provide active sites for effective reaction to take place. For example, $79 \%$ yield of biodiesel was obtained from palmitic acid using Al-MCM- $41(\mathrm{Si} / \mathrm{Al}=8)$ as the catalyst at a reaction temperature of $130{ }^{\circ} \mathrm{C}$, a reaction time of $2 \mathrm{~h}$, a catalyst concentration of $0.6 \mathrm{wt} . \%$, and a methanol to oil molar ratio of 60:1 [27]. However, in another study, the Zr30-MCM-41 catalyst produced $91.5 \%$ sunflower oil biodiesel yield at a reaction temperature of $200^{\circ} \mathrm{C}$, a reaction time of $6 \mathrm{~h}$, a catalyst concentration of $14.6 \mathrm{wt} . \%$, and an ethanol to oil molar ratio of 12:1 [28]. Additionally, 
$95.4 \%$ biodiesel yield was attained from waste cooking oil in the presence of $\mathrm{Mg} / \mathrm{ACM}-\mathrm{U}(\mathrm{Si} / \mathrm{Ce}=25)$ as the catalyst at a reaction temperature of $70{ }^{\circ} \mathrm{C}$, a reaction time of $6 \mathrm{~h}$, a catalyst concentration of $5 \mathrm{wt} . \%$, and a methanol to oil molar ratio of 9:1 [29]. Thus, the observed increase in biodiesel conversion rate was influenced by the incorporation of the active metals like $\mathrm{Ce}$ and $\mathrm{Zr}$ in the mesoporous silica framework. Moreover, metal incorporation enhances properties such as the addition of active sites, the regulation of the surface acidity of the support, and an improvement in catalyst stability [30-32].

Furthermore, the reaction parameters such as reaction temperature, reaction time, alcohol to oil ratio, and amount of catalyst has an influence on the biodiesel yield. Thus, it is essential to optimize the reaction conditions for an efficient conversion of triglycerides to biodiesel. Additionally, the reaction process for biodiesel production usually involves the study of one variable at a time (OVAT). Therefore, reaching inconclusive evidence for the possibility of one factor over the other with no provision for results on the interaction of the variables. For research involving the independent and dependent variables, the statistical design of experiments is a suitable alternative to measure the quantity effectively, efficiently, and economically [33,34]. Furthermore, contrary to the OVAT approach, design experts' use offers more accurate, valid, and reliable results on the effect of any influencing factor individually or when interacting with another factor on the biodiesel yield. Response surface methodology combined with central composite design (RSM-CCD) designs an experiment for optimum biodiesel yield [35]. The central composite design (CCD) is a suitable approach to study the effect of variables on biodiesel yield.

For example, Gupta et al. [36] employed the $2^{4}$ full-factorial CCD to study the effect of four reaction conditions, namely, methanol to oil molar ratio at a range of $3-9 \mathrm{~mol} / \mathrm{mol}$, reaction temperature of $35-65^{\circ} \mathrm{C}$, catalyst loading of $0.5-2 \mathrm{wt} . \%$, and reaction time $10-60 \mathrm{~min}$, making up a total number of 29 experiments. The study revealed that a maximum biodiesel yield of $97 \%$ was obtainable at a reaction temperature of $59^{\circ} \mathrm{C}$, catalyst loading of $0.51 \mathrm{wt} . \%$, a methanol to oil molar ratio of $5.9: 1$, and a reaction time of 30 mins. Krishnamurthy et al. [37] designed a total number of 30 experiments using RSM-CCD and obtained $96.929 \%$ and $98.93 \%$ biodiesel yield from dairy waste scum and Hydnocarpus wightiana oil at optimum conditions of reaction temperatures $58.56^{\circ} \mathrm{C}$ and $61.6^{\circ} \mathrm{C}$, reaction times of $119.684 \mathrm{~min}$ and $145.154 \mathrm{~min}$, methanol to oil molar ratios of $12.7: 1$ and $12.4: 1$, and catalyst dosages of $0.866 \mathrm{wt} . \%$ and $0.892 \mathrm{wt} . \%$, respectively. In another study conducted using CCD, the optimum reaction conditions for a maximum biodiesel yield of $85.94 \%$ were a reaction temperature of $89.21^{\circ} \mathrm{C}$, a reaction time of $6.48 \mathrm{~h}$, a catalyst concentration of $11 \mathrm{wt} . \%$, and a methanol to oil molar ratio of 29.14:1 [38].

Therefore, this present study investigated the impact of roasting and soaking pretreatment methods on Phoenix dactylifera L. seed oil yield, followed by a transesterification reaction of the extracted oil for fatty acid methyl ester (FAME) production. Thus, previously synthesized Ce-Zr/Al-MCM-41 monometallic and bimetallic catalysts prepared by impregnation and sonication methods were used $[39,40]$. Lastly, the optimum reaction conditions using RSM-CCD, the catalyst reusability, and the analysis of fuel properties were studied.

\section{Result and Discussion}

\subsection{Phoenix dactylifera L. Seeds Pre-Treatment and Extraction of Oil}

The roasted Phoenix dactylifera $\mathrm{L}$. seeds were found to have an uneven discoloration after oven treatment due to a lack of occasional tossing. However, the soaked seeds seem to have increased in size with the increase in water content. The size of the soaked seeds was efficiently reduced using a pair of scissors to cut the seeds into smaller pieces before the grinding process. Both the pretreatment methods were considered to increase the yield of oil content and simplify the grinding process of the hard Phoenix dactylifera L. seeds. It was found that soaking the seeds until soft enough to cut made the grinding easier with a household mill. Moreover, mechanical wear and tear and maintenance expenses may be minimized. Although the roasted seeds remained hard even after the prolonged drying process in a vacuum oven, the obtained oil yield of $7.83 \pm 0.16 \%$ was comparable to that of the soaked seeds, $7.04 \pm 0.25 \%$ per $50 \mathrm{~g}$ of the Phoenix dactylifera $\mathrm{L}$. seed powder. The maximum oil yield obtained for 
both the roasted and soaked seeds was with a particle size of $0.50 \mathrm{~mm}$. The oil yields obtained for both pretreatment methods were obtained from seeds with particle sizes of $0.50 \mathrm{~mm}, 0.25 \mathrm{~mm}, 1 \mathrm{~mm}$, and $2 \mathrm{~nm}$, in decreasing order. As such, the larger surface area of the smaller particle sizes allows for better solvent contact with the seeds, thereby providing access to the oil. Conversely, smaller particle sizes may cause channeling effects to occur-that is, the solvent runs down without penetrating the cell wall [10]. As a result of the uneven penetration of the solvent, the cell wall remains intact without extracting the oil contained in the unaffected areas of the seed. Thus, the highest oil yield found in this study using a particle size of $0.50 \mathrm{~mm}$ falls within the recommended range of $0.12-0.50 \mathrm{~mm}$ size for effective Phoenix dactylifera L. seed oil extraction [41].

However, the oil yield found after prolonged treatment of the seeds by soaking in water before extraction was found to be lower than that of the roasted seeds. Seed oil plays an essential role during the process of germination of the seeds, thereby decreasing the amount of oil content. As such, the decrease in the yield of the extracted oil could be attributed to the early germination of the Phoenix dactylifera L. seeds during the soaking period [42]. Moreover, the decrease in the oil yield from soaking pretreatment method could be correlated to possible moisture retention. Therefore, higher moisture content decreases the oil yield obtained using solvent extraction [43]. The triglyceride concentrations of the extracted Phoenix dactylifera L. seed oil calculated from the HPLC result for both the pretreatment methods were $96.58 \pm 031 \%$ for the roasted seeds and $90.99 \pm 0.66 \%$ for the soaked seeds. The observed triglyceride concentration of the roasted Phoenix dactylifera L. seeds was relatively higher than that of the soaked seeds, which was due to a moisture barrier in the seeds, thereby reducing the solubility between the structurally hydrophobic triglyceride compound and the hydrophobic solvent (n-hexane) [44]. The result obtained for the triglyceride concentration in roasted Phoenix dactylifera L. seed oil was close to the range 96.90-97.26\% [45].

\subsection{Catalytic Activity}

The activity of the catalysts used for the transesterification reaction to produce FAME was observed based on the set of fixed reaction conditions used. Figure 1 shows the FAME yield obtained using the Ce-Zr/Al-MCM-41 monometallic and bimetallic catalysts prepared by impregnation and sonication methods. The result shows that there was no significant difference in the FAME yield obtained using impregnated or sonicated catalysts. However, a difference was observed from the comparison of the FAME yield obtained using Al-MCM-41 support and catalysts. As the FAME yield increased upon the incorporation of $\mathrm{Ce}$ and $\mathrm{Zr}$ metals into the framework of the support. A regular trend was observed from a comparison of both the impregnated and sonicated catalyst catalysts. All the catalysts prepared by the sonication method resulted in higher FAME yield, except for the 7.5Ce-2.5Zr/Al-MCM-41 catalyst, which may be due to the accessibility of the suitable active sites responsible for the catalytic activity. Nevertheless, the catalyst with the highest FAME yield was obtained using the 5.0Ce-5.0Zr/AlMCM-41 sonicated bimetallic catalyst.

The FAME produced indicates the success of the reaction conducted using the extracted Phoenix dactylifera L. seed oil. Therefore, the oil has a potential as a feedstock for biodiesel production, which is comparable to other studies. For example, 30\% FAME yield was obtained from Phoenix dactylifera $\mathrm{L}$. seed oil at a reaction temperature $40{ }^{\circ} \mathrm{C}$, a reaction time $6 \mathrm{~h}$, and a methanol to oil molar ratio of 5:1 using Novozym $₫ 435$ as a catalyst [19]. In another study, 95.88\% FAME yield was obtained from Phoenix dactylifera L. seed oil using $\mathrm{KOH}$ as the catalyst, a methanol to oil molar ratio of $6: 1$, and a reaction time of $1 \mathrm{~h}[46]$. 


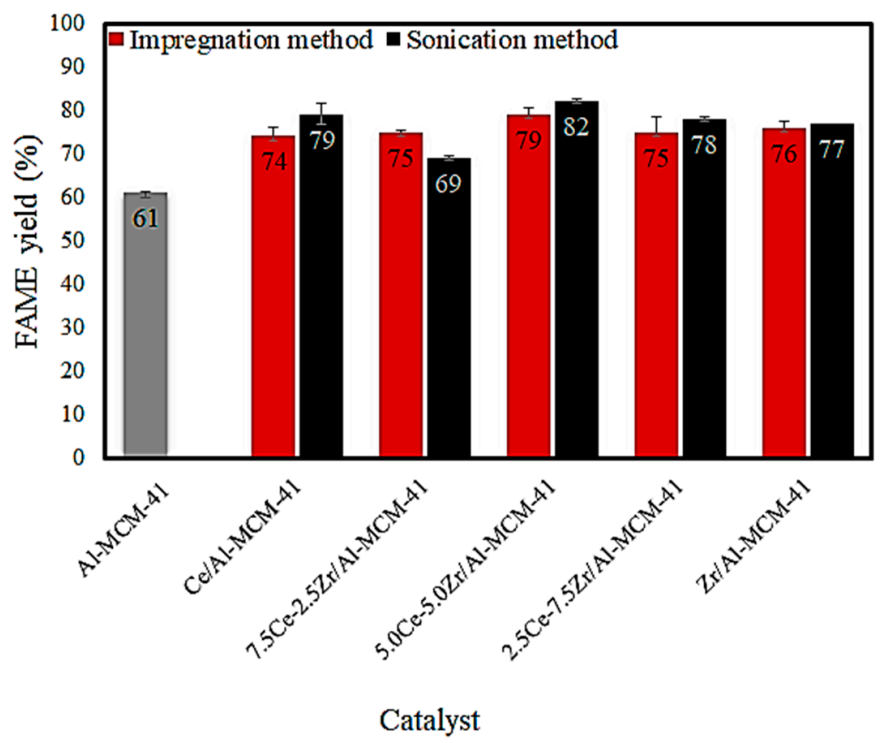

Figure 1. Phoenix dactylifera L. seed oil fatty acid methyl ester (FAME) yield using impregnated and sonicated Al-MCM-41 supported monometallic and bimetallic heterogeneous catalysts.

\subsection{Optimization of Reaction Conditions by Response Surface Methodology}

In this study, the optimization of FAME yield produced by the transesterification reaction of Phoenix dactylifera $\mathrm{L}$. seed oil was conducted in the presence of sonicated 5.0Ce-5.0Zr/Al-MCM-41 bimetallic heterogeneous catalyst. The statistical analysis was carried out using RSM-CCD to study the correlation between the independent variables and the FAME yield. Table 1 shows the generated result for the independent variables ranging from minimum to maximum, namely, reaction temperature $\mathrm{A}$ $\left(50-90^{\circ} \mathrm{C}\right)$, reaction time B $(1-5 \mathrm{~h})$, catalyst concentration C (1-5 wt. \%), and methanol to oil molar ratio $\mathrm{D}(4: 1$ to $12: 1 \mathrm{~mol} / \mathrm{mol})$, and that of the response which consists of the predicted and experimental FAME yield ranging from $73.68 \%$ to $93.34 \%$.

Table 1. Experimental design using the central composite design matrix for Phoenix dactylifera L. seed oil FAME.

\begin{tabular}{ccccccc}
\hline \multirow{2}{*}{ Run } & \multicolumn{3}{c}{ Independent Variables } & \multicolumn{2}{c}{ FAME Yield (\%) } \\
\cline { 2 - 7 } & A & B & C & D & Predicted & Actual \\
\hline 1 & 80 & 4 & 2 & 6 & 76.74 & 76.61 \\
2 & 70 & 1 & 3 & 8 & 77.38 & 77.68 \\
3 & 70 & 3 & 3 & 8 & 76.15 & 77.99 \\
4 & 70 & 3 & 3 & 8 & 79.48 & 77.99 \\
5 & 80 & 2 & 4 & 10 & 78.12 & 77.88 \\
6 & 70 & 3 & 3 & 8 & 78.77 & 77.99 \\
7 & 60 & 4 & 4 & 6 & 90.19 & 90.75 \\
8 & 60 & 2 & 4 & 10 & 81.88 & 82.33 \\
9 & 80 & 4 & 4 & 10 & 76.73 & 77.57 \\
10 & 50 & 3 & 3 & 8 & 79.92 & 79.60 \\
11 & 80 & 2 & 2 & 10 & 78.07 & 77.83 \\
12 & 60 & 2 & 4 & 6 & 93.15 & 93.02 \\
13 & 80 & 2 & 2 & 6 & 73.68 & 73.31 \\
14 & 80 & 4 & 4 & 6 & 86.65 & 86.39 \\
15 & 70 & 5 & 3 & 8 & 77.61 & 77.03 \\
16 & 70 & 3 & 3 & 8 & 79.10 & 77.99 \\
17 & 60 & 2 & 2 & 10 & 76.55 & 76.77 \\
18 & 70 & 3 & 3 & 12 & 76.83 & 76.34 \\
\hline
\end{tabular}


Table 1. Cont.

\begin{tabular}{ccccccc}
\hline \multirow{2}{*}{ Run } & \multicolumn{3}{c}{ Independent Variables } & \multicolumn{2}{c}{ FAME Yield (\%) } \\
\cline { 2 - 7 } & A & B & C & D & Predicted & Actual \\
\hline 19 & 70 & 3 & 5 & 8 & 93.34 & 92.45 \\
20 & 70 & 3 & 3 & 8 & 77.23 & 77.99 \\
21 & 90 & 3 & 3 & 8 & 76.24 & 76.29 \\
22 & 80 & 4 & 2 & 10 & 79.36 & 79.45 \\
23 & 60 & 4 & 2 & 10 & 74.95 & 74.77 \\
24 & 60 & 2 & 2 & 6 & 76.31 & 75.79 \\
25 & 70 & 3 & 1 & 8 & 76.49 & 77.10 \\
26 & 70 & & 3 & 8 & 77.22 & 77.99 \\
27 & 60 & 4 & 4 & 10 & 78.06 & 78.39 \\
28 & 60 & 4 & 2 & 6 & 75.27 & 75.46 \\
29 & 80 & 2 & 4 & 6 & 84.53 & 85.03 \\
30 & 70 & 3 & 3 & 4 & 83.97 & 84.19 \\
\hline
\end{tabular}

The regression coefficient $\left(R^{2}\right)$ was obtained from the analyzed experimental data. The fit summary for the response (FAME yield) suggested a second-order polynomial quadratic model (Table S1). The $R^{2}$ indicated a high chance of variability for the suggested model. The cubic model was found to be aliased as given by the heuristic scoring system. The quadratic model is the sequential sum of squares for the quadratic terms. The fit summary model shows the final quadratic regression equation, owing to the correlation between the reaction conditions and the FAME yield (\%), as seen in Equation (1):

$$
\begin{aligned}
\text { Yield }(\%) & =77.99-0.83 A-0.16 B+3.84 C-1.96 D+0.91 A B-1.38 A C \\
& +0.8-0.49-0.42 B D-2.92 C D-0.013 A^{2}-0.16 B^{2} \\
& +1.70 C^{2}+0.57 D^{2}
\end{aligned}
$$

where $A$ was the reaction temperature $\left({ }^{\circ} \mathrm{C}\right), B$ was the reaction time $(\mathrm{h}), C$ was the catalyst concentration (wt.\%), and $D$ is the methanol to oil molar ratio.

Table 2 shows the fitness of the model and significance in terms of the variables. The significance of each regression coefficient was determined using the probability value ( $p$-value). The values reported supported that the quadratic model was significant. Thus, the $p$-values were less than $0.05(95 \%$ confidence limit), indicating significant terms. The significant model terms were $A, C, D, A B, A C, A D$, $C D, C^{2}$, and $D^{2}$. However, the variables $B, B C, B D, A^{2}$, and $B^{2}$ were not significant. Thus, the software suggested that an improvement of the model may be achieved through model reduction.

However, the removal of the terms will decrease the $p$-value of the lack of fit. The goodness of the result relies on when the lack of fit was not significant relative to the pure error. The highest $F$-value of the model was that of the catalyst concentration (C) with a small $p$-value, which is attributed to the high significance of the corresponding coefficient [47] The predicted $R^{2}$ of 0.951 was in reasonable agreement with the adjusted $R^{2}$ of 0.967 , with a difference of less than 0.2 .

The $R^{2}$ indicates the relationship between the predicted and actual Phoenix dactylifera $\mathrm{L}$. seed oil FAME yield. The calculated values of the adjusted $R^{2}$ and predicted $R^{2}$ indicated the fitness of the model. The adequate precision is the signal to noise ratio that compares the range of predicted yield at the design points to the average predicted error, so model discrimination can be determined when the ratios are greater than 4 . Therefore, the adequate precision or signal to noise ratio greater than 4 is desirable [48]. In this study, adequate precision was found to be $\sim 30.02$, as in Table 1, indicating that the model can be used to navigate the design space. Another important factor considered for the evaluation process of the model's fitness was the coefficient of variation (CV). CV is a standard deviation expressed as the percentage of the mean. The value from the $\mathrm{CV}$ result must be below $10 \%$ for the model to be adequate. In this study, the value was found to be $1.17 \%$, indicating the suitability of the model for the FAME conversion. 
Table 2. Analysis of variance (ANOVA) of the quadratic model for the Phoenix dactylifera seed oil FAME.

\begin{tabular}{cccccc}
\hline Source & $\begin{array}{c}\text { Sum } \\
\text { of Squares }\end{array}$ & Df & Mean Square & F-Value & $p$-Value \\
\hline Model & 750.46 & 14 & 53.60 & 62.16 & $<0.0001$ \\
A: Temperature & 16.40 & 1 & 16.40 & 19.02 & 0.0006 \\
B: Time & 0.6273 & 1 & 0.6273 & 0.7274 & 0.4071 \\
C: Catalyst concentration & 353.28 & 1 & 353.28 & 409.69 & $<0.0001$ \\
D: Methanol: oil molar ratio & 92.36 & 1 & 92.36 & 107.10 & $<0.0001$ \\
AB & 13.14 & 1 & 13.14 & 15.24 & 0.0014 \\
AC & 30.31 & 1 & 30.31 & 35.14 & $<0.0001$ \\
AD & 12.53 & 1 & 12.53 & 14.53 & 0.0017 \\
BC & 3.76 & 1 & 3.76 & 4.36 & 0.0541 \\
BD & 2.81 & 1 & 2.81 & 3.25 & 0.0914 \\
CD & 136.07 & 1 & 136.07 & 157.80 & $<0.0001$ \\
A $^{2}$ & 0.0043 & 1 & 0.0043 & 0.0050 & 0.9447 \\
$\mathrm{~B}^{2}$ & 0.6912 & 1 & 0.6912 & 0.8016 & 0.3848 \\
C $^{2}$ & 78.92 & 1 & 78.92 & 91.52 & $<0.0001$ \\
$D^{2}$ & 8.83 & 1 & 8.83 & 10.24 & 0.0060 \\
Residual & 12.93 & 15 & 0.8623 & & \\
Lack of Fit & 4.32 & 10 & 0.4318 & 0.2506 & 0.9701 \\
Pure Error & 8.62 & 5 & 1.72 & & \\
Cor Total & 763.40 & 29 & & & \\
\hline$R^{2}=0.9831 ;$ adjusted $R^{2}=0.9672 ;$ predicted $R^{2}=0.9512 ;$ adequate precision $=30.0197 ;$ coefficient of variation \\
$(\mathrm{CV})=1.17 \%$. & & & &
\end{tabular}

Figure 2 shows the graphical illustration of the result obtained from actual and predicted yield data for Phoenix dactylifera L. seed oil FAME. The actual data fits the model better than the predicted data. However, the observed data shows an acceptable correlation between the predicted and actual results obtained.

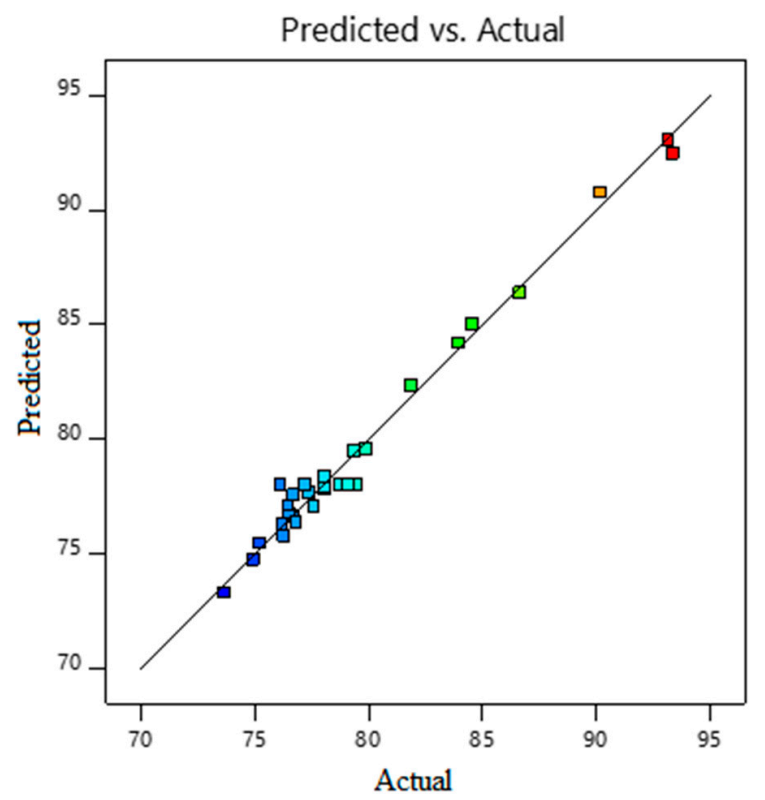

Figure 2. Predicted versus actual value plot for Phoenix dactylifera L. seed oil FAME.

Figure 3 shows three-dimensional (3D) RSM model surface plots for the interactive effects of two independent variables at a time on the response. The remaining variables were kept in a fixed position at central levels. Figure 3 a shows the effect of the interaction between the reaction temperature and the reaction time on FAME yield, at fixed catalyst concentration and methanol to oil molar ratio. The increase in FAME yield to $\sim 80 \%$ can be seen with an increase in reaction temperature and a reaction 
time. Concurrently, the decreases in FAME yield was not substantial, with an increase in reaction time and reaction temperature towards the center (above $65^{\circ} \mathrm{C}$ ). However, a significant decrease was observed with further increase in reaction temperature. As such, the FAME yield gradually decreased with an increase in reaction temperature above methanol boiling temperature. The decrease in FAME yield at higher temperatures is related to the evaporation of the solvent [49]. However, the maximum FAME yield was obtained at $80{ }^{\circ} \mathrm{C}$ using a PTSA/MCM-41 (PTSA, p-toluene sulfonic) catalyst in a membrane reactor [47]. Therefore, the evaporation of methanol at a high reaction temperature resulting in FAME yield decrease may be correlated to the reactor used.

Figure $3 \mathrm{~b}$ shows the effect of interaction between the reaction temperature and catalyst concentration on FAME yield at constant reaction time and methanol to oil molar ratio. The 3D plot shows that the FAME yield increased as the catalyst concentration increased towards $4 \mathrm{wt} . \%$ and reaction temperature close to $65{ }^{\circ} \mathrm{C}$. The observed gradual increase in FAME yield was from $76 \%$ to $84 \%$ with an increase in catalyst concentration. Thus, the lowest yield was obtained with a decrease in catalyst concentration and further increase in reaction temperature. The low FAME yield is attributed to the incomplete transesterification reaction for methyl ester conversion with the inadequate catalyst concentration [6].

Figure $3 c$ shows the interaction between reaction temperature and methanol to oil molar ratio while the other variables were kept constant. The FAME yield found was in the range of $77 \%$ to $82 \%$ from the interaction. A linear decrease in FAME yield was observed with a decrease in reaction temperature and methanol to oil molar ratio. From the 3D plot, the highest FAME yield was found when the methanol to oil molar ratio was slightly above $6: 1$ at a reaction temperature closer to $60^{\circ} \mathrm{C}$. However, when the amount of methanol was further increased at a higher reaction temperature, the FAME yield decreased. Excess methanol (above the stoichiometric 3 moles) is required for the reversible transesterification reaction to shift forward and favor the production. However, when the methanol exceeds the adequately required amount, it may lead to difficult phase separation for the glycerol and the ester layers resulting in low FAME yield. Another possible reason for the decrease in yield with an increase in methanol to oil molar ratio and reaction temperature may be due to the methanol and heterogeneous catalyst's insufficient miscibility. Consequently, the methanol accumulates at the surface of the catalyst and evaporates with an increase in reaction temperature [50].
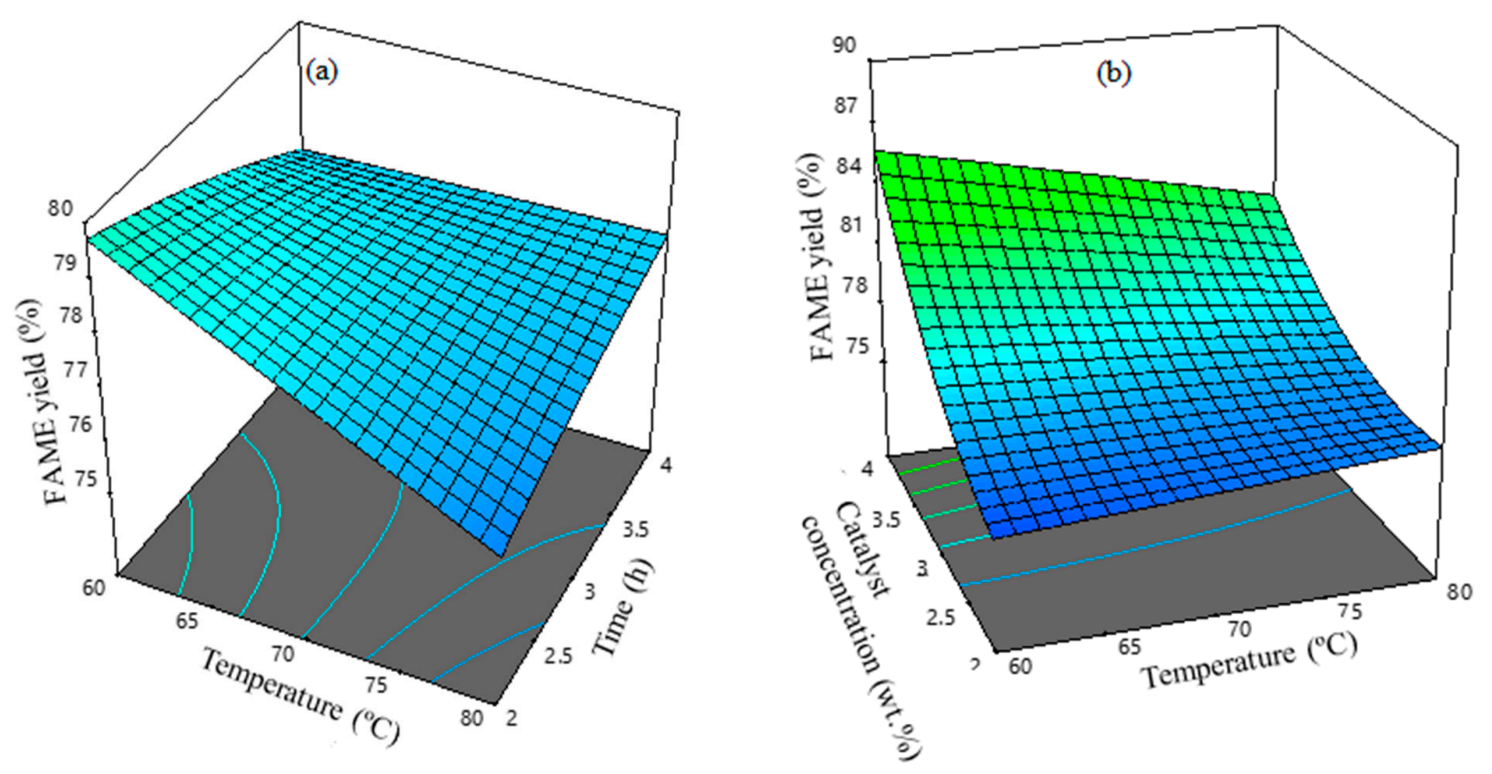

Figure 3. Cont. 

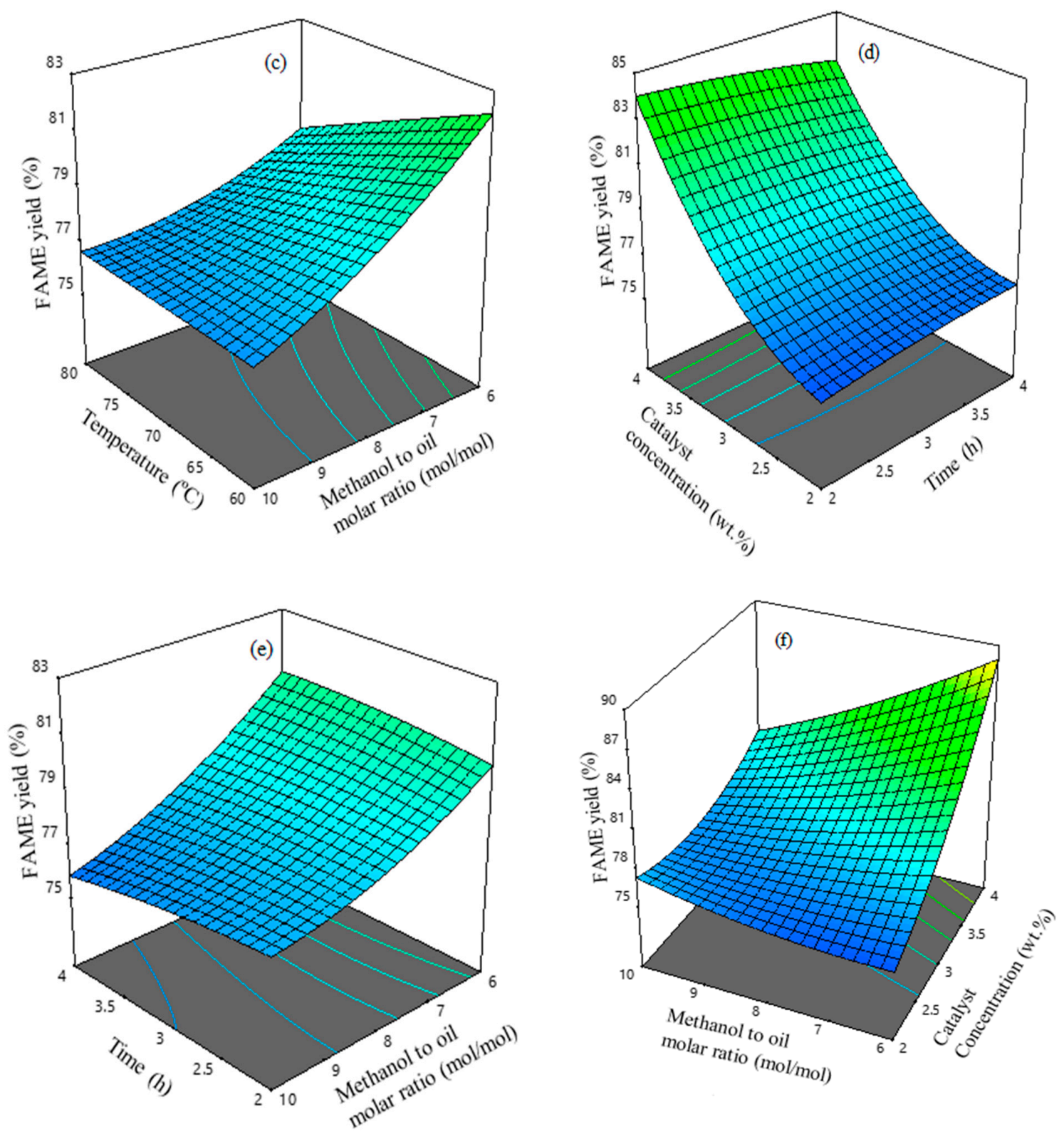

Figure 3. 3D plots for the interaction effects of reaction conditions on Phoenix dactylifera L. seed oil FAME yield obtained using5.0Ce-5.0Zr/Al-MCM-41 bimetallic catalyst. [(a) reaction temperature vs. reaction time, (b) reaction temperature vs. catalyst concentration, (c) reaction temperature vs. methanol to oil molar ratio, (d) reaction time vs. catalyst concentration, (e) reaction time vs. methanol to oil molar ratio, and (f) catalyst concentration vs. methanol to oil molar ratio].

Figure $3 \mathrm{~d}$ shows the 3D plots of the interaction between the reaction time and catalyst concentration, at a fixed reaction temperature and methanol to oil molar ratio. A positive interaction was observed with the gradual increase as the FAME yield increased from $76 \%$ to $82 \%$, with an increase in reaction time and catalyst concentration. However, the highest FAME yield was obtained when the reaction time was below $4 \mathrm{~h}$. Further increase in reaction time may lead to a reverse reaction, which will result in lower FAME yield. Figure 3e shows the 3D plot for the interaction between the reaction time and methanol to oil molar ratio. It was observed that the FAME yield obtained increased with a decrease in methanol to oil molar ratio. The FAME yield ranges from $76 \%$ to $80 \%$, which favors low methanol to oil molar ratio slightly above 6:1 with an increase in reaction time. Another significant interaction between two of the variables was observed in Figure $3 \mathrm{f}$ for the interaction between catalyst concentration and methanol to oil molar ratio. It was observed that an increase in the catalyst concentration and a 
decrease in methanol to oil molar ratio increased the FAME yield. The lowest yield was obtained when the methanol to oil molar ratio exceeded 8:1. From the result, the optimum FAME yield obtained was $76 \%$ to $88 \%$. Therefore, the best interactive effect for the production was that of the methanol to oil molar ratio and catalyst concentration, considering the highest FAME yield obtained in Figure 3a-f.

The numerical optimization for Phoenix dactylifera L. seed oil FAME yield was carried out to ascertain the optimum reaction conditions. The requirement was for the goals to be set at either equal to, maximum, minimum, target to a specific value or in range of the independent variables' set values for the highest yield response. The desirability function was employed to achieve optimum FAME yield. The options were set as 'in range' by default for the operating conditions and 'maximum' for FAME yield for the minimum and maximum independent variables. The set goals combine to form a desirability function close to 1 . The closer the desirability to 1 , the better the generated solution given. The optimum temperature of $60.5^{\circ} \mathrm{C}$, reaction time of $3.8 \mathrm{~h}$, catalyst concentration of $4 \mathrm{wt} . \%$ and methanol to oil molar ratio of 6.2:1 were required for the optimum FAME yield of $94.24 \%$ as predicted by the software when all the conditions were set "in range".

The predicted yield observed was close to the highest yield obtained from the experimental study, indicating the model's fitness. Validation of the predicted result was carried out at optimum reaction conditions, and the FAME yield was found to be $93.83 \pm 0.29 \%$. The difference between the experimental and predicted yield was within the acceptable range, thus, implying that the designed model was suitable for the experimental study. For example, Samart et al. [51] reported the predicted yield of $84.0 \%$ and experimental yield of $83.1 \%$ from the optimization study conducted using $\mathrm{SO}_{3} \mathrm{H}-\mathrm{MCM}-41$ and rubber seed oil for biodiesel production. The reaction was conducted at a reaction temperature of $129.6^{\circ} \mathrm{C}$, a reaction time of $48 \mathrm{~h}$, a catalyst concentration of $14.5 \mathrm{wt} . \%$, and a $16: 1$ methanol to oil molar ratio. In another study, $96.6 \%$ predicted yield and $95.5 \%$ experimental yield were obtained at a reaction temperature of $153^{\circ} \mathrm{C}$, a reaction time of $120 \mathrm{~min}$, a catalyst concentration of $5.06 \mathrm{wt} . \%$, and 0.266 molar composition of 3-mercaptopropyl (methyl) dimethoxy siloxane, MPMDS using $\mathrm{SO}_{3} \mathrm{H}-\mathrm{MCM}-41$ as a catalyst [52].

\subsection{Reusability Studies}

The stability of the catalyst was determined by conducting reusability studies using Phoenix dactylifera $\mathrm{L}$. in the presence of a 5.0Ce-5.0Zr/Al-MCM-41 bimetallic catalyst under optimized reaction conditions at a reaction temperature of $60.5^{\circ} \mathrm{C}$, a reaction time $3.8 \mathrm{~h}$, catalyst loading of $4 \mathrm{wt} . \%$, and a methanol to oil molar ratio of 6.2:1 (Figure 4). The reusability studies show that the catalyst activity was maintained with high Phoenix dactylifera seed oil FAME conversion for the first 5 runs. The high activity observed after the catalyst was regenerated was due to the proper treatment during the washing steps (hot distilled water and n-hexane). As a result, the catalyst performance for the first 5 runs was similar, indicating its economic viability. The findings from this study were similar to [53], where the treatment of [CTA]MCM-41 catalyst with water and methanol resulted in 5 runs with minor deactivation for the transesterification of canola oil. Additionally, the loss in catalytic activity for $\mathrm{Na} / \mathrm{Zr}-\mathrm{SBA}-15$ catalyst after washing with benzene was not significant for 3 runs [26]. The authors reported that the washing step was not adequate due to the observed loss in the FAME yield. However, in this study, a slight but gradual decrease was observed due to the amassing of the heavy triglyceride, which in turn slows the activity of the catalyst. Thus, in run 6, a remarkable decrease in the FAME yield was found, as it was less than $90 \%$ lower than run 5 . The significant decrease in FAME yield is attributed to the clogging of the activity sites $[25,54]$. 


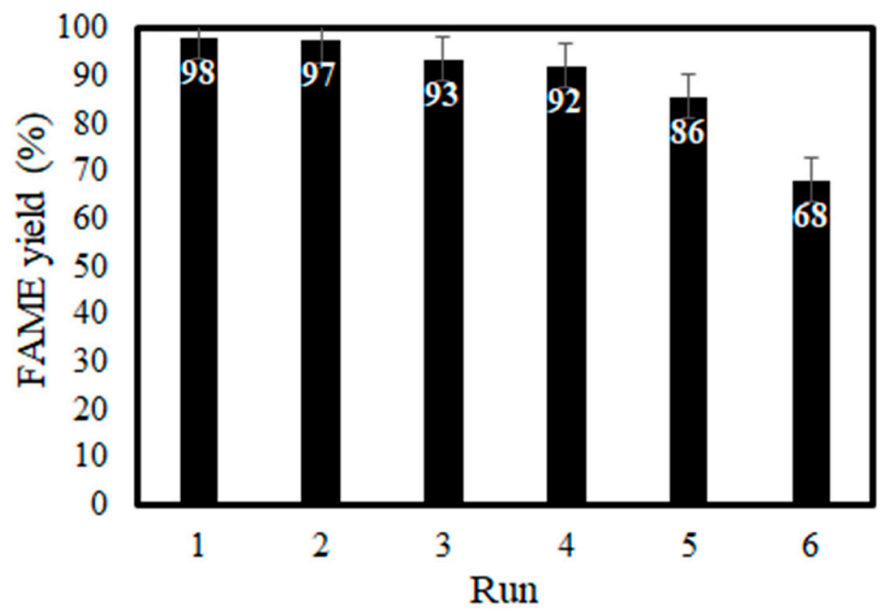

Figure 4. Reusability studies for a 5.0Ce-5.0Zr/Al-MCM-41 bimetallic heterogeneous catalyst at a reaction temperature $60.5^{\circ} \mathrm{C}$, a reaction time of $3.8 \mathrm{~h}$, a methanol to oil molar ratio of $6.2: 1$ and catalyst loading of 4 wt.\%.

\subsection{Physicochemical Properties}

Table 3 shows the properties of the extracted Phoenix dactylifera L. seed oil and the produced FAME, which includes the acid value, density, iodine value, saponification value, oxidation stability, cetane number, flash point, pour point, total glycerol, and free glycerol. The quantity expressed in milligrams of potassium hydroxide $(\mathrm{KOH})$ per gram of oil or sample is referred to as acid value. The acid value of the oil was found to be $1.95 \mathrm{mg} \mathrm{KOH} / \mathrm{g}$, which was lower than the range of $2.47-2.55 \mathrm{mg} \mathrm{KOH} / \mathrm{g}$, reported in [55]. However, the acidity was higher than the specified limit in ASTM D651 and EN14214 standards. Therefore, the oil was not suitable to be used directly as an engine fuel before the FAME conversion.

In contrast, the acid value of the FAME found in this study was within the acceptable range specified in both the American and European standards. The lower the acid value, the higher the FAME quality maintenance during storage [11,56]. Density refers to the mass in grams per volume of a sample. The density is linearly correlated to the carbon chain length, molecular mass, and saturation level $[17,57]$. The density of the oil and FAME in this study was found to be within the EN and ASTM standard range. Iodine value refers to the quantity of iodine $\left(I_{2}\right)$ in grams absorbed per $100 \mathrm{~g}$ of the sample. Iodine value is the measure of the degree of unsaturated (double bonds) fatty acid present. The high iodine value correlates to the higher degree of unsaturation of the fatty acid in the sample as a result of oxidation. The saponification value is related to the carbon chain length. The higher saponification value of the seed oil is an indication of shorter chain length. The saponification value is inversely proportional to the carbon chain length and the molecular weight $[56,57]$.

The level of unsaturation or number of double bonds of fatty acids (especially polyunsaturated) is the major factor for oxidative stability determination $[13,58]$. In this study, the degree of unsaturation (DU) for the FAME was calculated to be $19.27 \%$, and the SFA, MUFA, and PUFA were found to be $80.64 \%, 16.69 \%$, and $1.29 \%$, respectively. Therefore, the oxidation stability found obtained complies with the EN and ASTM standard limits. The cetane number is directly proportional to the engine ignition [59]. Higher cetane number signifies better ignition. As such, the calculated cetane number was found to be above the minimum limits for both EN and ASTM standards. Furthermore, the pour point refers to the temperature at which fuel flow is inhibited. The pour point found in this study was the same as the value reported in studies $[7,18,46]$. The flashpoint is defined as the minimum temperature at which the vapor of the sample ignites when exposed to an ignition source. Thus, the ignition power of fuel under specified conditions is determined by the degree of the flashpoint. Moreover, the obtained flashpoint is a measure for the determination of methanol residue in FAME compared to the standard limits. The flashpoint obtained in this study was considerably high, indicating a good storage quality [59]. 
Table 3. Physicochemical properties of Phoenix dactylifera L. seed oil, produced using a sonicated 5.0Ce-5.0Zr/Al-MCM-41 bimetallic heterogeneous catalyst.

\begin{tabular}{|c|c|c|c|c|c|c|c|c|c|c|c|}
\hline \multirow{2}{*}{$\begin{array}{l}\text { Properties } \\
\text { References }\end{array}$} & \multicolumn{3}{|c|}{$\begin{array}{c}\text { Phoenix dactylifera } \mathrm{L} . \\
\text { Seed Oil }\end{array}$} & \multicolumn{6}{|c|}{$\begin{array}{c}\text { Phoenix dactylifera } \text { L. Seed Oil } \\
\text { FAME }\end{array}$} & \multicolumn{2}{|c|}{ Standard Limits } \\
\hline & This study & {$[60]$} & {$[46]$} & This study & {$[46]$} & [7] & {$[21]$} & [59] & {$[18]$} & ASTM D6750 & EN14214 \\
\hline Acid value (mg KOH/g) & 1.95 & $0.50 *$ & 1.23 & 0.46 & 0.1 & 0.21 & 0.27 & 0.26 & - & $0.8 \max$ & $0.5 \max$ \\
\hline $\begin{array}{l}\text { Density }\left(\mathrm{g} / \mathrm{cm}^{3}\right) \\
\text { at } 20{ }^{\circ} \mathrm{C}\end{array}$ & 0.909 & 0.917 & 0.92 & 0.889 & 0.8781 & 0.881 & 0.872 & 0.892 & 0.877 & $0.82-0.9$ & $0.86-0.9$ \\
\hline Iodine value & 35.53 & 56.76 & 47.66 & 37.44 & 47.66 & - & - & - & 46 & - & $120 \max$ \\
\hline $\begin{array}{l}\text { Saponification value } \\
\quad(\mathrm{mg} \mathrm{KOH} / \mathrm{g})\end{array}$ & 225.8 & 205.97 & 212 & 224.4 & 224 & - & - & - & 224 & - & - \\
\hline $\begin{array}{c}\text { Oxidation stability (h) } \\
\text { at } 110^{\circ} \mathrm{C}\end{array}$ & - & $17.2-22.9$ & 一 & 19.94 & - & - & - & - & - & $3 \min$ & $6 \mathrm{~min}$ \\
\hline Cetane number & - & - & 61.32 & 62.20 & 59.75 & 61.12 & 56 & 59.31 & 60.3 & $47 \mathrm{~min}$ & $51 \mathrm{~min}$ \\
\hline Flash point ${ }^{\circ} \mathrm{C}$ & - & - & 186 & 96 & 141 & 142 & 155 & 145 & 140 & $93 \mathrm{~min}$ & $120 \mathrm{~min}$ \\
\hline Pour point ${ }^{\circ} \mathrm{C}$ & - & - & 3 & -1 & -1 & -1.23 & - & -2.1 & -1 & - & - \\
\hline Total glycerol & - & - & 0.11 & 0.01 & 0.11 & 0.162 & - & 0.21 & - & $0.24 \max$ & $0.25 \max$ \\
\hline Free glycerol & - & - & 0.015 & 0.015 & 0.015 & 0.011 & - & 0.011 & - & $0.02 \max$ & $0.02 \max$ \\
\hline
\end{tabular}




\section{Materials and Methods}

\subsection{Materials}

Phoenix dactylifera L. (date) fruits were supplied by "Green Diamond" importers in Selangor, Malaysia. All the reagents in this study, such as analytical grade (AR) methanol ( $99 \%$ purity), isopropanol ( $\geq 99.8$ purity), and n-hexane purchased from Merck, and nonadecanoate methyl ester (C19:0, $\geq 99.5 \%$ purity, Sigma Aldrich) were used without further purification. Al-MCM-41 ( $>97.0 \%$ purity, ACS materials) was calcined at $500{ }^{\circ} \mathrm{C}$ and used as a support for Ce and $\mathrm{Zr}$ monometallic and bimetallic catalysts prepared by impregnation and sonication methods as described in $[39,40]$, respectively (Table 4).

Table 4. Al-MCM-41 supported catalysts used for biodiesel production from Phoenix dactylifera L. seed oil.

\begin{tabular}{ccccc}
\hline & \multicolumn{2}{c}{ Metal Concentration } & \multicolumn{2}{c}{ References } \\
\hline Catalyst & Ce (wt.\%) & $\mathrm{Zr}($ wt. $\%)$ & Impregnation method & Sonication method \\
Ce/Al-MCM-41 & 10 & - & Not published \\
7.5Ce-2.5Zr/Al-MCM-41 & 7.5 & 2.5 & Not published & {$[40]$} \\
$5.0 \mathrm{Ce}-5.0 \mathrm{Zr} /$ Al-MCM-41 & 5 & 5 & [39] & {$[40]$} \\
$2.5 \mathrm{Ce}-7.5 \mathrm{Zr} / \mathrm{Al}-\mathrm{MCM}-41$ & 2.5 & 7.5 & Not published & {$[40]$} \\
Zr/Al-MCM-41 & - & 10 & {$[39]$} & Not published \\
\hline
\end{tabular}

\subsection{Pre-Treatment of Seeds and Extraction of the Seed Oil}

The Phoenix dactylifera L. seed was washed with water to remove any dirt and remaining pulp. The seeds were divided into two for drying (roasting) and soaking (in water) pretreatment methods. For the drying pretreatment method, the washed seeds were spread on a metal tray, placed in an oven at $40^{\circ} \mathrm{C}$, and dried overnight. For the soaking pretreatment method, the washed seeds were soaked in water at room temperature $\left(25^{\circ} \mathrm{C}\right)$ for 3 days in a $1000 \mathrm{~mL}$ beaker. The beaker was covered using a perforated foil paper for air passage. The oven-dried seeds were ground to powder using a strong granulator (Wensui Plastics Machine Group, Model: WSGP-230) and a universal cutting mill combination (FRITSCH PULVERISTTE25/ PULVERISTTE19), whereas the size of the softened soaked seeds was reduced manually by cutting with a pair of steel scissors, and they were ground to powder using a dry mill (Panasonic Blender MX-GM1011H). The soaking pretreatment method ground seeds were dried overnight in a convection oven (Memmert) at $35^{\circ} \mathrm{C}$ with air circulation (using FAN control at a speed of $100 \%$ ). The ground seed powder obtained from both pretreatment methods were separately sieved to pass a particle size of $0.25,0.5,1.0$, and $2.0 \mathrm{~mm}$ using stainless steel sieves on a mechanical shaker (CISA: BA $300 \mathrm{~N}$ ). The Phoenix dactylifera L. seed oil was extracted using n-hexane as a solvent, at a solvent to seed ratio of $4: 1$, a temperature of $70^{\circ} \mathrm{C}$, and an extraction time of $7 \mathrm{~h}$ as reported in [17]. The oil was separated from the solvent using a vacuum rotary evaporator (BUCHI Model: VIVO RT2, $360 \mathrm{mbar}$ ) at a temperature of $40^{\circ} \mathrm{C}$. The percentage yield of extracted seed oil was calculated on a dry weight basis using Equation (2).

$$
\text { Total extraction yield }(\%)=\frac{\text { Weight of oil extracted }}{\text { Weight of seed powder }} \times 100
$$

\subsection{Transesterification Reaction Process}

The transesterification reaction was carried out using the Ce-Zr/Al-MCM-41 impregnated and sonicated monometallic and bimetallic catalysts in a $50 \mathrm{~mL}$ three-neck round bottom flask. First, the desired amounts of the catalyst and the methanol were measured and mixed at $50^{\circ} \mathrm{C}$ for $30 \mathrm{~min}$ before the addition of the preheated Phoenix dactylifera $\mathrm{L}$. seed oil. Then the reaction was stirred at a reaction temperature of $65^{\circ} \mathrm{C}$, a reaction time of $1 \mathrm{~h}$, a methanol to oil molar ratio of $6: 1$, and a catalyst 
concentration of $2.5 \mathrm{wt} . \%$ (of the oil used). Subsequently, the reaction was stopped after completion and allowed to cool to room temperature; the catalyst was then filtered with a $0.45 \mu \mathrm{m}$ syringe filter. The filtrate was centrifuged to aid the phase separation and allowed to stand overnight to separate the fatty acid methyl ester (FAME) produced from glycerol. The FAME was then washed with hot distilled water (that was boiled to $80^{\circ} \mathrm{C}$ ) and dried in an oven to remove excess moisture. The FAME yield was taken as a measure for the selection of the catalyst with higher activity under the same reaction conditions for optimization studies.

\subsection{Optimization and Reusability Studies}

The central composite design combined with response surface methodology (RSM-CCD) in Design-Expert version 11.0.5.0 software (Stat-Ease, Inc., USA) was used. The experiments were selected to study the effect of the reaction conditions on the FAME yield. The experiment was designed using a $2^{4}$ full factorial for four independent variables. The independent variables were selected by considering previous studies on biodiesel production using a heterogeneous catalyst, such as in [61]. The independent variables selected were labeled $A$ to $D$, standing for reaction temperature, reaction time, catalyst loading, and methanol to oil molar ratio, Table 5.

Table 5. Variables levels for the optimization study of Phoenix dactylifera L. seed oil FAME.

\begin{tabular}{cccccccc}
\hline \multirow{2}{*}{$\begin{array}{c}\text { Independent } \\
\text { Variables }\end{array}$} & Units & Label & \multicolumn{5}{c}{ Range and Level } \\
\cline { 4 - 8 } & & & $\mathbf{- 2}$ & $\mathbf{- 1}$ & $\mathbf{0}$ & $\mathbf{+ 1}$ & $\mathbf{+ 2}$ \\
\hline Temperature & ${ }^{\circ} \mathrm{C}$ & $\mathrm{A}$ & 50 & 60 & 70 & 80 & 90 \\
Time & $\mathrm{h}$ & $\mathrm{B}$ & 1 & 2 & 3 & 4 & 5 \\
Catalyst loading & $\mathrm{wt.} \%$ & $\mathrm{C}$ & 1 & 2 & 3 & 4 & 5 \\
Methanol to oil ratio & $\mathrm{mol} / \mathrm{mol}$ & $\mathrm{D}$ & 4 & 6 & 8 & 10 & 12 \\
\hline
\end{tabular}

The FAME yield was selected as the dependent variable (response). The experiment was conducted in a randomized order at a full range for 30 observations. The total number of the experiment designed was calculated using full factorial design as $\left[2^{4}+(2 \times 4)+6\right]$, where 4 represents the total of the number of independent variables, and the number 6 is indicating the replicates to accommodate for standard error of prediction. Thus, the experiment consists of $2^{\mathrm{k}}$ factorial points, $2 \mathrm{k}$ axial points, and $\mathrm{k}_{\mathrm{c}}$ center points. The experimental data obtained using the RSM-CCD was subsequently analyzed by the analysis of variance (ANOVA). An empirical model was developed to correlate the response variable and the independent variables based on second-order polynomial to analyze the effect of the variables interaction [33], as follows in Equation (3):

$$
Y=\beta_{0}+\sum_{i=1}^{k} \beta_{i} X_{i}+\sum_{i=1}^{k} \beta_{i i} X_{i}^{2}+\sum_{i=1}^{k-1} \sum_{j=2}^{k} \beta_{i j} X_{i} X_{j}+\varepsilon
$$

where $Y$ is the response factor (FAME yield); $\beta_{0}$ is an intercept; $\beta_{i}, \beta_{i i}$, and $\beta_{j}$ are the linear, quadratic and interactive regression coefficients of the model, respectively; $x_{i}, x_{i i}$, and $x_{j}$ represent the independent variables; and $\varepsilon$ represents the model-associated random error.

Reusability studies were conducted using 5.0Ce-5.0Zr/Al-MCM-41 bimetallic catalyst at optimized reaction conditions. After the transesterification reaction, the catalyst was separated from the product mixture by filtration on a vacuum filter, washed first with hot distilled water $\left(80^{\circ} \mathrm{C}\right)$, before a second chemical treatment with n-hexane. The catalyst was centrifuged for $10 \mathrm{~min}$ and dried in an oven at $100{ }^{\circ} \mathrm{C}$ for $5 \mathrm{~h}$. The dried catalyst was reused for the subsequent FAME conversion after each reaction. The FAME produced was separated, washed, and kept for further analysis. 


\subsection{Physicochemical Properties}

The oil concentration was analyzed using the triglyceride (TG) method as a reference standard for comparison. The analysis was conducted using a high-performance liquid chromatography (HPLC) equipped with a refractive index detector (HPLC-RID, Shimadzu Model, RID-10A) using a mobile phase of n-hexane/isopropanol in a ratio of $97: 3(\mathrm{v} / \mathrm{v})$. The column temperature was set at $40{ }^{\circ} \mathrm{C}$ with a flow rate of $1 \mathrm{~mL} / \mathrm{min}$ and an injection volume of $20 \mu \mathrm{L}$ (Column: Shim Pack $150 \mathrm{~m}, 4.6 \mathrm{~mm}, 5 \mu \mathrm{m}$ film). After the analysis, the oil concentration was calculated as in Equation (4):

$$
C R=\left(\frac{\frac{A R}{M R}}{\frac{A S}{M S}}\right) \times C S
$$

where $C R$ is the concentration of sample reaction mixture in $(\mathrm{mol} / \mathrm{L}), A R$ is the oil peak of the sample reaction mixture, $M R$ is the mass of sample reaction mixture $(\mathrm{mg}), A S$ is the oil peak area of the oil standard (triglyceride), MS is the mass of oil standard (triglyceride, $\mathrm{mg}$ ), and CS is the oil concentration of the standard (mol/L).

The analysis of FAME from Phoenix dactylifera L. seeds oil was carried out following the BS EN14103:2011 testing method for the determination of ester and linolenic acid methyl ester content [62]. A gas chromatography instrument (Agilent Technologies, 7890A GC Systems) equipped with a flame ionization detector (FID), a spit-spitless inlet (split ratio 50:1 at a split rate of 100:1 mL/min), and a temperature programmable oven was used. The capillary column was a model from Agilent Columns, DB-23 (Model: J \& W 122-2362) with a length of $60 \mathrm{~m}$, an internal diameter of $250 \mu \mathrm{m}$, and a film thickness of $0.25 \mu \mathrm{m}$. The operation conditions for the chromatographic analyses started with a column temperature of $60^{\circ} \mathrm{C}$, which was held for $2 \mathrm{~min}$ and raised to $200^{\circ} \mathrm{C}$. The maximum oven temperature of $240{ }^{\circ} \mathrm{C}$ was held for $7 \mathrm{mins}$ at a ramping rate of $5{ }^{\circ} \mathrm{C} / \mathrm{min}$. The carrier gas was helium at $60{ }^{\circ} \mathrm{C}$, a constant flow rate of $2 \mathrm{~mL} / \mathrm{min}$, and a constant pressure mode of $\sim 230 \mathrm{kPa}$. Approximately $100 \mathrm{mg}$ of the homogenized sample was weighted in a $10 \mathrm{~mL}$ sample bottle, and nonadecanoic methyl ester (C19:0) was used as the internal standard. The mixture was diluted with $10 \mathrm{~mL}$ toluene. $1 \mu \mathrm{L}$ of this solution was injected into the GC-FID. For identification of the peaks from the chromatogram obtained after the analysis, the retention time of the sample peaks of the FAME mix was compared, and the FAME yield was calculated using Equation (5):

$$
\% \text { FAME yield }=\frac{E A-A E I}{A E I} \times \frac{C E I \times W E I}{m} \times 100
$$

where $E A$ is the total peak area of the methyl esters, $A E I$ is the peak area of the internal standard (nonadecanoic methyl ester, C19:0), CEI is the loading of the internal standard used ( $\mathrm{mg} / \mathrm{mL}), W E I$ is the weight $(\mathrm{mL})$ of the internal standard used, and $m$ is the mass of sample used $(\mathrm{mg})$.

The fuel properties analyzed include acid value, iodine value, peroxide value, saponification value, density, specific gravity, oxidative stability, cetane number, pour point, flash point, total glycerol, and free glycerol. The acid value, iodine value, and peroxide value were determined, as in [20]. Moisture content was found following ASTM D2216 to calculate the weight difference before and after drying the sample in a vacuum oven at $105^{\circ} \mathrm{C}$ for $24 \mathrm{~h}$. The saponification value was obtained using the ASTM D5558-95 standard method. Density and specific gravity were determined using the Anton Paar analyzer following the ASTM D7042. Oxidative stability was obtained using Metrohm 873 Biodiesel Rancimat at $110^{\circ} \mathrm{C}$. The cetane number was determined using the correlation equation in [63]. Pour point was determined using the CPP 5Gs ISL analyzer. The ASTM 93 standard method was used to measure the flashpoint on a CLA 5 flashpoint analyzer. The total and free glycerol determination was conducted by following the ASTM D6584 standard method. The FAME profile obtained from the GC-FID analysis was used to calculate the total saturated fatty acid (SFA), monounsaturated fatty acid (MUFA), and polyunsaturated fatty acid (PUFA). The degree of unsaturation was calculated using the values obtained for MUFA and PUFA [63]. 


\section{Conclusions}

Phoenix dactylifera L. seeds were pretreated by roasting and soaking methods for higher oil yield extraction. Compared to roasting, the soaking pretreatment method simplified the grinding process with no significant difference in the oil yield obtained (7.83\% and $7.04 \%$, respectively). The highest FAME yield was obtained using a 5.0Ce-5.0Zr/Al-MCM041 bimetallic catalyst prepared by the sonication method. The RSM-CCD statistical technique predicted the optimum FAME yield of $94.24 \%$ and an experimental yield of $93.83 \%$ at a reaction temperature of $60.5^{\circ} \mathrm{C}$, a reaction time of $3.8 \mathrm{~h}$, a catalyst concentration of $4 \mathrm{wt} . \%$, and a methanol to oil molar ratio of $6.2: 1 \mathrm{~mol} / \mathrm{mol}$. Deactivation of the catalyst was observed in run 6, with a significant decrease in FAME yield after 5 cycles. However, high catalytic activity was obtained for the first 5 runs, thus indicating that the catalyst can be regenerated and reused several times without significant loss in catalytic activity. The fuel properties of the Phoenix dactylifera $\mathrm{L}$. seed oil FAME were within the ASTM D6751 and EN14214 standards limits.

Supplementary Materials: The following are available online at http://www.mdpi.com/2073-4344/10/7/764/s1, Table S1: Sequential model sum of squares for Phoenix dactylifera seed oil FAME.

Author Contributions: Z.I.J., methodology, data curation, and writing-original draft preparation; A.R., supervision, review, and editing; K.J., supervision, software, and validation; N.M.Y., supervision. All authors have read and agreed to the published version of the manuscript.

Funding: This research was funded by Yayasan Universiti Teknologi PETRONAS, grant number 015LC0-145 and The APC was funded by Yayasan Universiti Teknologi PETRONAS, grant number 015LC0-145.

Acknowledgments: This study was supported by the Yayasan Universiti Teknologi PETRONAS research grant (015LC0-145). The financial support from Universiti Teknologi PETRONAS under the graduate assistantship scheme is acknowledged. The authors also acknowledged the support provided by Malaysian Ministry of Higher Education through the HICoE award to CBBR.

Conflicts of Interest: The authors declare no conflict of interest. The funders had no role in the design of the study; in the collection, analyses, or interpretation of data; in the writing of the manuscript; or in the decision to publish the results.

\section{References}

1. Gebremariam, S.N.; Marchetti, J.M. Economics of biodiesel production: Review. Energy Convers. Manag. 2018, 168, 74-84. [CrossRef]

2. Karmakar, B.; Halder, G. Progress and future of biodiesel synthesis: Advancements in oil extraction and conversion technologies. Energy Convers. Manag. 2019, 182, 307-339. [CrossRef]

3. Tsita, K.G.; Kiartzis, S.J.; Ntavos, N.K.; Pilavachi, P.A. Next generation biofuels derived from thermal and chemical conversion of the Greek transport sector. Therm. Sci. Eng. Prog. 2020, 17, 100387. [CrossRef]

4. Endalew, A.K.; Kiros, Y.; Zanzi, R. Heterogeneous catalysis for biodiesel production from Jatropha curcas oil (JCO). Energy 2011, 36, 2693-2700. [CrossRef]

5. Rezania, S.; Oryani, B.; Park, J.; Hashemi, B.; Yadav, K.K.; Kwon, E.E.; Hur, J.; Cho, J. Review on transesterification of non-edible sources for biodiesel production with a focus on economic aspects, fuel properties and by-product applications. Energy Convers. Manag. 2019, 201, 112155. [CrossRef]

6. Krishnamurthy, K.N.; Sridhara, S.N.; Ananda Kumar, C.S. Synthesis and optimization of Hydnocarpus wightiana and dairy waste scum as feed stock for biodiesel production by using response surface methodology. Energy 2018, 153, 1073-1086. [CrossRef]

7. Jamil, F.; Al-Muhatseb, A.H.; Myint, M.T.Z.; Al-Hinai, M.; Al-Haj, L.; Baawain, M.; Al-Abri, M.; Kumar, G.; Atabani, A.E. Biodiesel production by valorizing waste Phoenix dactylifera L. Kernel oil in the presence of synthesized heterogeneous metallic oxide catalyst (Mn@MgO-ZrO 2 ). Energy Convers. Manag. 2018, 155, 128-137. [CrossRef]

8. Rahimi, V.; Shafiei, M. Techno-economic assessment of a biorefinery based on low-impact energy crops: A step towards commercial production of biodiesel, biogas, and heat. Energy Convers. Manag. 2019, 183, 698-707. [CrossRef]

9. Joshi, S.; Hadiya, P.; Shah, M.; Sircar, A. Techno-economical and Experimental Analysis of Biodiesel Production from Used Cooking Oil. Biophys. Econ. Resour. Qual. 2019, 4, 2. [CrossRef] 
10. Aris, N.A.; Norhuda, I.; Adeib, I.S. Extraction of Phoenix dactylifera (Mariami) seeds oil using supercritical carbon dioxide (SC-CO 2 ). Int. J. Chem. Environ. Eng. 2013, 4, 32-37.

11. Shalaby, E.A. A Review of Selected Non-Edible Biomass Sources as Feedstock for Biodiesel Production. In Biofuels-Status and Perspective; Biernat, K., Ed.; IntechOpen: London, UK, 2015; pp. 3-20.

12. Kamil, M.; Ramadan, K.; Olabi, A.G.; Ghenai, C.; Inayat, A.; Rajab, M.H. Desert Palm Date Seeds as a Biodiesel Feedstock: Extraction, Characterization, and Engine Testing. Energies 2019, 12, 3147. [CrossRef]

13. Mahmud, I.A.; Mirghani, M.E.S.; Alkhatib, M.F.R.; Yusof, F.; Shahabuddin, M.; Rashidi, O.; Daoud, J.I. Nutrients depictions of Barhi date palm (Phoenix dactylifera L.) kernels. Int. Food Res. J. 2017, 24, 325-334.

14. Soliman, S.S.; Al-Obeed, R.S.; Ahmed, T.A. Physico-chemical characteristics of oil produced from seeds of some date palm cultivars (Phoenix dactylifera L). J. Environ. Biol. 2015, 36, 455.

15. Bouallegue, K.; Allaf, T.; Besombes, C.; Younes, R.B.; Allaf, K. Phenomenological modeling and intensification of texturing/grinding-assisted solvent oil extraction: Case of date seeds (Phoenix dactylifera L.). Arab. J. Chem. 2019, 12, 2398-2410. [CrossRef]

16. Waezi-Zadeh, M.; Ghazanfari, A.; Noorbakhsh, S. Finite element analysis and modeling of water absorption by date pits during a soaking process. J. Zhejiang Univ. Sci. B 2010, 11, 482-488. [CrossRef] [PubMed]

17. Jamil, F.; Al-Muhtaseb, A.H.; Al-Haj, L.; Al-Hinai, M.A.; Hellier, P.; Rashid, U. Optimization of oil extraction from waste "date pits" for biodiesel production. Energy Convers. Manag. 2016, 117, 264-272. [CrossRef]

18. Amani, M.A.; Davoudi, M.S.; Tahvildari, K.; Nabavi, S.M.; Davoudi, M.S. Biodiesel production from Phoenix dactylifera as a new feedstock. Ind. Crops Prod. 2013, 43, 40-43. [CrossRef]

19. Al-Zuhair, S.; Taher, H.; Al Dhaheri, S.; Wajeeh, S.; Nour, M.; El-Najjar, E. Biodiesel Production from Oils Extracted from Date Pits. Green Sustain. Chem. 2017, 07, 48-56. [CrossRef]

20. Ali, M.A.; Al-Hydary, I.A.; Al-Hattab, T.A. Nano-magnetic catalyst CaO-Fe3O4 for biodiesel production from date palm seed oil. Bull. Chem. React. Eng. Catal. 2017, 12, 460-468. [CrossRef]

21. Farooq, M.; Ramli, A.; Naeem, A.; Mahmood, T.; Ahmad, S.; Humayun, M.; Islam, M.G.U. Biodiesel production from date seed oil (Phoenix dactylifera L.) via egg shell derived heterogeneous catalyst. Chem. Eng. Res. Des. 2018, 132, 644-651. [CrossRef]

22. Abu-Jrai, A.M.; Jamil, F.; Al-Muhtaseb, A.H.; Baawain, M.; Al-Haj, L.; Al-Hinai, M.; Al-Abri, M.; Rafiq, S. Valorization of waste Date pits biomass for biodiesel production in presence of green carbon catalyst. Energy Convers. Manag. 2017, 135, 236-243. [CrossRef]

23. Changmai, B.; Sudarsanam, P.; Rokhum, L. Biodiesel production using a renewable mesoporous solid catalyst. Ind. Crops Prod. 2019, 145, 111911. [CrossRef]

24. Avhad, M.R.; Marchetti, J.M. Innovation in solid heterogeneous catalysis for the generation of economically viable and ecofriendly biodiesel: A review. Catal. Rev. Sci. Eng. 2016, 58, 157-208. [CrossRef]

25. Vardast, N.; Haghighi, M.; Dehghani, S. Sono-dispersion of calcium over Al-MCM-41used as a nanocatalyst for biodiesel production from sunflower oil: Influence of ultrasound irradiation and calcium content on catalytic properties and performance. Renew. Energy 2019, 132, 979-988. [CrossRef]

26. Chen, W.-K.; Tseng, H.-H.; Wei, M.-C.; Su, E.-C.; Chiu, I.-C. Transesterification of canola oil as biodiesel over Na/Zr-SBA-15 catalysts: Effect of zirconium content. Int. J. Hydrogen Energy 2014, 39, 19555-19562. [CrossRef]

27. Carmo, A.C.; de Souza, L.K.C.; da Costa, C.E.F.; Longo, E.; Zamian, J.R.; da Rocha Filho, G.N. Production of biodiesel by esterification of palmitic acid over mesoporous aluminosilicate Al-MCM-41. Fuel 2009, 88, 461-468. [CrossRef]

28. Jiménez-Morales, I.; Santamaría-González, J.; Maireles-Torres, P.; Jiménez-López, A. Calcined zirconium sulfate supported on MCM-41 silica as acid catalyst for ethanolysis of sunflower oil. Appl. Catal. B Environ. 2011, 103, 91-98. [CrossRef]

29. Dehghani, S.; Haghighi, M. Sono-dispersion of MgO over Al-Ce-doped MCM-41 bifunctional nanocatalyst for one-step biodiesel production from acidic oil: Influence of ultrasound irradiation and Si/Ce molar ratio. Ultrason. Sonochem. 2019, 54, 142-152. [CrossRef]

30. Dehghani, S.; Haghighi, M. Sono-enhanced dispersion of CaO over Zr-Doped MCM-41 bifunctional nanocatalyst with various $\mathrm{Si} / \mathrm{Zr}$ ratios for conversion of waste cooking oil to biodiesel. Renew. Energy 2020, 153, 801-812. [CrossRef] 
31. Jiménez-López, A.; Jiménez-Morales, I.; Santamaría-González, J.; Maireles-Torres, P. Biodiesel production from sunflower oil by tungsten oxide supported on zirconium doped MCM-41 silica. J. Mol. Catal. A Chem. 2011, 335, 205-209. [CrossRef]

32. Dehghani, S.; Haghighi, M. Sono-dispersed MgO over cerium-doped MCM-41 nanocatalyst for biodiesel production from acidic sunflower oil: Surface evolution by altering Si/Ce molar ratios. Waste Manag. 2019, 95, 584-592. [CrossRef] [PubMed]

33. Ahmad, T.; Danish, M.; Kale, P.; Geremew, B.; Adeloju, S.B.; Nizami, M.; Ayoub, M. Optimization of process variables for biodiesel production by transesterification of flaxseed oil and produced biodiesel characterizations. Renew. Energy 2019, 139, 1272-1280. [CrossRef]

34. Talebian-Kiakalaieh, A.; Amin, N.A.S.; Zarei, A.; Noshadi, I. Transesterification of waste cooking oil by heteropoly acid (HPA) catalyst: Optimization and kinetic model. Appl. Energy 2013, 102, 283-292. [CrossRef]

35. Kostić, M.D.; Bazargan, A.; Stamenković, O.S.; Veljković, V.B.; McKay, G. Optimization and kinetics of sunflower oil methanolysis catalyzed by calcium oxide-based catalyst derived from palm kernel shell biochar. Fuel 2016, 163, 304-313. [CrossRef]

36. Gupta, J.; Agarwal, M.; Dalai, A.K. Optimization of biodiesel production from mixture of edible and nonedible vegetable oils. Biocatal. Agric. Biotechnol. 2016, 8, 112-120. [CrossRef]

37. Krishnamurthy, K.N.; Sridhara, S.N.; Ananda Kumar, C.S. Optimization and kinetic study of biodiesel production from Hydnocarpus wightiana oil and dairy waste scum using snail shell $\mathrm{CaO}$ nano catalyst. Renew. Energy 2020, 146, 280-296. [CrossRef]

38. Tang, Z.E.; Lim, S.; Pang, Y.L.; Ong, H.C. Optimisation of corncob based heterogeneous acid catalysed biodiesel synthesis using response surface methodology. In Proceedings of the IOP Conference Series: Materials Science and Engineering, Kuala Lumpur, Malaysia, 13-14 August 2018; IOP Publishing: Bristol, UK, 2018; Volume 458, p. 12082.

39. Jibril, Z.I.; Ramli, A.; Jumbri, K. Al-MCM-41 Based Catalysts for Transesterification of Jatropha Oil to Biodiesel: Effect of Ce and Zr. J. Japan Inst. Energy 2018, 97, 200-204. [CrossRef]

40. Jibril, Z.I.; Ramli, A.; Jumbri, K. Preparation and Characterization of Ce-Zr/Al-MCM-41 Bimetallic Catalyst for Transesterification of Jatropha Oil to Biodiesel. In Proceedings of the IOP Conference Series: Earth and Environmental Science, Kuala Lumpur, Malaysia, 16-18 January 2018; IOP Publishing: Bristol, UK, 2018; Volume 168, p. 12013.

41. Ali, M.A.; Al-hattab, T.A.; Al-hydary, I.A. Extraction of Date Palm Seed Oil by Soxhlet Apparatus. Adv. Eng. Technol. 2015, 8, 261-271.

42. Abdul Afiq, M.J.; Abdul Rahman, R.; Che Man, Y.B.; Al-Kahtani, H.A.; Mansor, T.S.T. Date seed and date seed oil. Int. Food Res. J. 2013, 20, 2035-2043.

43. Efthymiopoulos, I.; Hellier, P.; Ladommatos, N.; Kay, A.; Mills-Lamptey, B. Effect of solvent extraction parameters on the recovery of oil from spent coffee grounds for biofuel production. Waste Biomass Valorization 2019, 10, 253-264. [CrossRef]

44. Tuntiwiwattanapun, N.; Tongcumpou, C.; Wiesenborn, D. Optimization of alcoholic soybean oil extraction as a step towards developing in-situ transesterification for fatty acid isopropyl esters. Ind. Crops Prod. 2016, 94, 189-196. [CrossRef]

45. Besbes, S.; Blecker, C.; Deroanne, C.; Lognay, G.; Drira, N.E.; Attia, H. Quality characteristics and oxidative stability of date seed oil during storage. Food Sci. Technol. Int. 2004, 10, 333-338. [CrossRef]

46. Fadhil, A.B.; Alhayali, M.A.; Saeed, L.I. Date (Phoenix dactylifera L.) palm stones as a potential new feedstock for liquid bio-fuels production. Fuel 2017, 210, 165-176. [CrossRef]

47. Xu, W.; Gao, L.; Wang, S.; Xiao, G. Biodiesel production in a membrane reactor using MCM-41 supported solid acid catalyst. Bioresour. Technol. 2014, 159, 286-291. [CrossRef] [PubMed]

48. Zhang, Y.; Niu, S.; Lu, C.; Gong, Z.; Hu, X. Catalytic performance of $\mathrm{NaAlO} 2 / \gamma-\mathrm{Al} 2 \mathrm{O} 3$ as heterogeneous nanocatalyst for biodiesel production: Optimization using response surface methodology. Energy Convers. Manag. 2020, 203, 112263. [CrossRef]

49. Nguyen, H.C.; Nguyen, M.L.; Wang, F.-M.; Juan, H.-Y.; Su, C.-H. Biodiesel production by direct transesterification of wet spent coffee grounds using switchable solvent as a catalyst and solvent. Bioresour. Technol. 2020, 296, 122334. [CrossRef] [PubMed]

50. Baskar, G.; Aberna Ebenezer Selvakumari, I.; Aiswarya, R. Biodiesel production from castor oil using heterogeneous Ni doped ZnO nanocatalyst. Bioresour. Technol. 2018, 250, 793-798. [CrossRef] 
51. Samart, C.; Karnjanakom, S.; Chaiya, C.; Reubroycharoen, P.; Sawangkeaw, R.; Charoenpanich, M. Statistical optimization of biodiesel production from para rubber seed oil by SO3H-MCM-41 catalyst. Arab. J. Chem. 2019, 12, 2028-2036. [CrossRef]

52. Karnjanakom, S.; Kongparakul, S.; Chaiya, C.; Reubroycharoen, P.; Guan, G.; Samart, C. Biodiesel production from Hevea brasiliensis oil using SO3H-MCM-41 catalyst. J. Environ. Chem. Eng. 2016, 4, 47-55. [CrossRef]

53. Pirouzmand, M.; Nikzad-kojanag, B.; Seyed-Rasulzade, S.K. Surfactant containing Ca/MCM-41 as a highly active, green and reusable catalyst for the transesterification of canola oil. Catal. Commun. 2015, 69, $196-201$. [CrossRef]

54. Sahani, S.; Roy, T.; Chandra Sharma, Y. Clean and efficient production of biodiesel using barium cerate as a heterogeneous catalyst for the biodiesel production; kinetics and thermodynamic study. J. Clean. Prod. 2019, 237, 117699. [CrossRef]

55. Abdalla, R.S.M.; Albasheer, A.A.; ElHussein, A.R.M.; Gadkariem, E.A. Physico-chemical characteristics of date seed oil grown in Sudan. Am. J. Appl. Sci. 2012, 9, 993-999.

56. Shanab, S.M.M.; Hanafy, E.A.; Shalaby, E.A. Biodiesel production and antioxidant activity of different Egyptian date palm seed cultivars. Asian J. Biochem. 2014, 9, 119-130. [CrossRef]

57. Azeem, M.W.; Hanif, M.A.; Al-Sabahi, J.N.; Khan, A.A.; Naz, S.; Ijaz, A. Production of biodiesel from low priced, renewable and abundant date seed oil. Renew. Energy 2016, 86, 124-132. [CrossRef]

58. Knothe, G. Production and Properties of Biodiesel from Algal Oils. In Algae for Biofuels and Energy; Borowitzka, M.A., Moheimani, N.R., Eds.; Springer: Dordrecht, The Netherlands, 2013; pp. 207-221, ISBN 9789400754799.

59. Al-Muhtaseb, A.H.; Jamil, F.; Al-Haj, L.; Zar Myint, M.T.; Mahmoud, E.; Ahmad, M.N.M.; Hasan, A.O.; Rafiq, S. Biodiesel production over a catalyst prepared from biomass-derived waste date pits. Biotechnol. Rep. 2018, 20, e00284. [CrossRef]

60. Nehdi, I.A.; Sbihi, H.M.; Tan, C.P.; Rashid, U.; Al-Resayes, S.I. Chemical Composition of Date Palm (Phoenix dactylifera L.) Seed Oil from Six Saudi Arabian Cultivars. J. Food Sci. 2018, 83, 624-630. [CrossRef]

61. Ranucci, C.R.; Colpini, L.M.S.; Monteiro, M.R.; Kothe, V.; Gasparrini, L.J.; Alves, H.J. Preparation, characterization and stability of KF/Si-MCM-41 basic catalysts for application in soybean oil transesterification with methanol. J. Environ. Chem. Eng. 2015, 3, 703-707. [CrossRef]

62. Singh, D.; Chopra, A.; Kumar, R.; Sastry, M.I.S.; Patel, M.B.; Basu, B. Response factor correction for estimation of ester content in biodiesel. Chromatographia 2014, 77, 165-169. [CrossRef]

63. Talebi, A.F.; Tabatabaei, M.; Chisti, Y. BiodieselAnalyzer@: A user-friendly software for predicting the properties of prospective biodiesel. Biofuel Res. J. 2014, 1, 55-57. [CrossRef] 